\title{
About Management and Efficiency of Agri-Business Organisations
}

\author{
Hrabrin Bachev* \\ Institute of Agricultural Economics, Sofia, Bulgaria
}

\begin{abstract}
Unprecedented development in theory of economic organisations in past decades has brought about to significant evolution in understanding of essence and efficiency of agri-business organizations. Nevertheless traditional approach for assessing management and efficiency of economic organisationsis ("black-box" approach, through "technical or financial efficiency" of production factors, "productivity of employed resources") is widly used. Concequently it cannot be excplained: why there are so many organizations performing with great variation in efficiency for long period of time. This paper incorporates achievements of interdisciplinary New Institutional Economics and suggests a framework for assessing management and efficiency of organizations for agri-biusiness and innovation. According to this new approach we have to study firm and farm as a governing rather than as production structure; assess comparative efficiency of alternative market, contract, internal, and hybrid modes of governance; take into account transaction costs and institutional, behavioral, dimensional, technological and natural factors; enrich (reformulate) criteria of economic efficiency of business organization; and better determine effective horizontal and vertical boundaries of business organisations. Specificity in the area of agri-business research and innovations is also clarified. Effective boundaries of different governing modes are assessed, and needs and forms for public intervention in agrarian research and innovation are clarified.
\end{abstract}

Keywords: Modes of governance; Agri-business organizations; Agrarian innovations

\section{Introduction}

Unprecedented development in teconomic theory in past decades has brought about to significant evolution in understanding of essence and efficiency of business organisations [1-3]. Nevertheless partial approaches for assessing managemenmt and efficiency of firms/farms and other economic organisations in agriculture are predominately used. For instance, efficiency of business organizations in agriculture is usually evaluated (only) through "technical" and/or "financial" efficiency of production factors ("productivity of employed resources"). What is more, comparisons are made of levels of efficiency across business organizations of different type, sectors and countries independent to specific economic, institutional or natural environment.

Traditional approach can not give answer to question: why there are so many organizations performing with a great variation in efficiency for a long period of time. If efficiency of a particular organisation is low, there will always be a strong private (management) or public (competition) mechanism for reallocation of resources to more effective application, and in the long run there will be only "effective" organizations governing resources on socially acceptable ("marginal") level of efficiency. Furthermore, the traditional approach estimates and compares levels of efficiency of different organisations without even looking for answering the question: why there is such a variety of organizations in a country, sub-sector, geographical region etc. - unregistered organizations, one-person and family enterprises, registered cooperatives and firms of different kind, small and large organisations etc. Therefore, in the narrow framework restricting efficiency of economic organisations to production costs, it is neither possible to understand economic logic of diverse business organisation nor to assess their comparative efficiency and complementarities. This paper incorporates achievements of interdisciplinary New Institutional Economics (combining Economics, Organisation, Law, Sociology, Behavioral Sciences) and suggests adequate framework for assessing efficiency of business organizations in agriculture.

\section{Business Organizations as Governance Structure}

Newly developing methodology of New Institutional Economics explains diverse economic organizations with their role to govern relations between individual agents and minimize transaction costs (Coase; Williamson). Carrying out economic activity and related exchange is usually associated with significant (transaction) costs. For instance, there are costs for complying with institutional requirements, finding best prices and partners; negotiating conditions of exchange; contract writing and registration; enforcing negotiated terms; dispute resolution (though court or another way); adjusting or termination along with evolving conditions etc.

Division and specialization of labor, and related exchange and cooperation, open up enormous opportunities for increasing productivity and welfare. They create possibilities and incentives for deepening specialization and exchanges. However, they are also associated with additional transaction costs. High of costs for external exchange make it more profitable to carry out division and cooperation of labor (transaction) within certain organization (firm, coperative) instead across market. However, internal management of transactions is also associated with costs (directing, stimulating and supervising hired labor; coordination and controlling partners activity) which restricts unlimited expansion of borders of (internal) organization. Thus a transaction (activity) will be carried in an organization if costs are lower than for governing that transaction across market or in another organization [1].

Most activity and exchange could usually be governed through a variety of alterative forms. One extreme for manager is to specialize exclusively in governing of market transactions (rather than production management). Another extreme is a close one-person or group firm

*Corresponding author: Hrabrin Bachev, Institute of Agricultural Economics, Sofia, Bulgaria, Tel: 3592-971-3913; E-mail: hbachev@yahoo.com

Received August 18, 2014; Accepted September 03, 2014; Published September 13, 2014

Citation: Bachev H (2014) About Management and Efficiency of Agri-Business Organisations . Int J Econ Manag Sci 3: 188. doi: 10.4172/2162-6359.1000188

Copyright: ( 2014 Bachev $\mathrm{H}$. This is an open-access article distributed under the terms of the Creative Commons Attribution License, which permits unrestricted use, distribution, and reproduction in any medium, provided the original author and source are credited. 
- e.g. farmer(s) employ only own resources and labor, and consume entire product. Between these poles there is spectrum of feasible modes for governing of activity and exchange. Depending on comparative efficiency of practically possible forms preference will be given to one or another organisation of activity/exchange.

Consequently, distribution of overall activities among different business organizations and markets will be determined by comparative costs for using various governing arrangements as the most efficient one(s) minimizing total (internal and external) transaction cost will prevail in the long run. Economic efficiency of business organizations must take into account not only capacity to minimize production costs, but also ability to economize on transaction costs . Moreover, both (current) costs for using individual organizations and long-term costs for development (initiation, maintenance, modernization, liquidation) have to be taken into account.

If execution of activity and exchange were not associated with transaction costs ("zero transaction costs") then mode of organization would have no economic importance [3,4]. Individuals would govern their relationships with same efficiency though free market (adapting to price movements), and private modes of different types (contracts, firms), and collective decision-making (cooperative, association), and a nationwide hierarchy (single private/state company). Then technological opportunities for economies of scale/scope (maximum productivity of resources, "internalization of externalities") would be easily achieved. All information for the effective potential of transactions (optimization of resources, meeting demands, respecting rights/rules) would be cost-free available to everybody, and individuals would cost-free define new rights, and trade owned resources of mutual benefit until exhausting possibilities for increasing productivity and welfare ("Pareto efficiency").

However, often high transaction costs make it difficult/block otherwise efficient (beneficial) for all parties activity/exchange. Since economic activity is connected with transaction costs, "rational" agents will seek, chose, and develop modes of organization of activity/ exchanges which maximize transacting benefits and minimize transaction costs. Type of economic organization is crucial since various governing modes give unequal possibilities for participants to explore social and technological opportunities (meeting demands, economies of scale /scope), coordinate and adapt transactions, stimulate acceptable behaviour of counterparts, control and protect from unwanted expropriation investments. In long-run inefficient forms will be abandoned and only effective modes for organization will dominate. Efficiency of different types of business organizations cannot be properly understood and assessed without analyzing their comparative production and governance potential.

\section{Factors for Choice of Business Form}

Individual forms of governance have specific advantages and disadvantages for protection of rights of participants, coordination and stimulation of socially needed economic activity. They are alternative but not equally efficient modes for organization of individual activity/ transactions since they have different features to coordinate, control, and stimulate (maximize benefits from, minimize costs of) transactions.

Free market has big coordination and incentive advantages ("invisible hand of market", "power of competition"), and provides "unlimited" opportunities to benefit from specialization and exchange. However, market governance could be associated with high uncertainty, risk, and costs due to lack of adequate information, price instability, possibility for opportunistic behaviour, "missing market" situation.
Special contract form ("private ordering") permits better coordination, intensification, and safeguard of activity/exchange. However, it may require large costs for specification, writing down and registration of contracts, controlling contract implementation, adjustments with constant changes in conditions, enforcement and disputing of negotiated terms.

Internal (ownership) organization allows greater flexibility and control on activity (direct coordination, adaptation, enforcement, dispute resolution by fiat). However, extension of internal mode beyond family and small-partnership boundaries command significant costs for coalition (finding partners, design, registration, restructuring), and current management (collective decision-making, control on coalition members opportunism, direction, supervision and motivation of hired labour).

Separation of ownership from management (cooperative, corporation) gives enormous opportunities for growth in productivity and transacting efficiency - internal division and specialization of labor; exploration of economies of scale/scope; introduction of innovation; diversification; risk sharing; investing in product promotion, relations with counterparts and authorities. However, it could be connected with huge transaction costs for decreasing information asymmetry between management and shareholders, decision-making, controlling opportunism, adaptation. Cooperative and the non-for profit form also suffers from low capability for internal long-term investment due to non-for-profit goals and non-tradable character of shares ("horizon problem").

Which one of principle forms of organisation of activity and transactions will be used depends on comparative efficiency of practically possible alternatives. Transaction costs have two behavioral origins: individual's bounded rationality and opportunism (Wiliamson). Agents do not possess full information about the economic system (price ranges, demands, trade opportunities, development trends) since collection and processing of such information is very expensive/ impossible (multiple markets, future events, partners intention for cheating). In order to optimize decision-making they have to spend for "increasing imperfect rationality" - data collection, analysis, forecasting, training, consultation.

Agents are also given to opportunism and if there is opportunity for a party to get non-punishably extra benefit/rent from exchange, they would probably take advantage of. Three major forms of opportunism can be distinguished: pre-contractual ("adverse selection") - when some of partners use "information asymmetry" to negotiate better contract terms; post-contractual ("moral hazard") - when some counterpart takes advantage of impossibility for full observation on activities (by others, third-party) or when takes "legal advantages" of unpredicted changes in exchange conditions (costs, prices, formal regulations). Third form ("free ride") occurs in development of large organizations where individual benefits are not-proportional to individual efforts/ costs. Trend is everyone to expect others to invest in organizational development, and benefit from new organization in case of success [5].

It is often very costly or impossible to distinguish opportunistic from non-opportunistic behavior because of bounded rationality. Agents have to protect rights, investments, and transactions from hazard of opportunism through: ex-ante efforts to find reliable counterpart and design efficient mode for partners credible commitments; expost investments for overcoming (through monitoring, controlling, stimulating cooperation) of possible opportunism during contract execution stage. 


\section{Choice of economic organization also depends on number of additional factors}

First, personal characteristics of agents - preferences, ideology, knowledge, capability, risk-aversion, reputation, trust, "contractual" power. For instance, business organization is often restricted to family partnership; in some cultures, cooperative is preferred mode of economic organization. If enterpreuneur is a good manager he will design, control and run bigger organization adapted to specific needs managing more internal (hired labor) and outside (market, contract) transactions. A risk-taker prefers risky but more productive forms -bank credit for new profitable venture. When counterparts are family members or close friends there is no need for complex organization since relations are "governed" by high mutual confidence, good will, and common interests. Benefits could take forms of monetary/ non-monetary income, profit, indirect revenue, pleasure of selfemployment or family enterprise, enjoyment in involvement in farming, environment preservation etc. activity, increased leisure/free time.

Second, institutional environment - formal and/or informally imposed social order ("rules of game") and associated costs. Often choice of governing mode is (pre)determined by institutional restrictions as some forms for carrying business activities, inputs supply, trade of output could be socially unacceptable, too expensive or illegal . (External) institutional environment considerably affects level of transaction costs and thus organizational choice. For instance, in conditions of stable and well-functioning public regulations and effective mechanisms for laws and contract enforcement, preference is given to spotlight and classical/standard contracts. When rights on major resources are not well-defined and enforced, primitive, unproductive and unsustainable organizations, personalized and/or over-integrated forms, undeveloped and missing markets prevail.

Third, natural and technological factors like non-separability and interdependency of activity, technological economies of scale/scope. In rare cases there is one practically possible form for governance of activity. For example, in dispersed paddy agriculture water supply cannot be conducted by individual farmers (high interdependency, non-separability of water use) and since earliest period water use organization developed as public project. In most businesses it is almost impossible to find cases where form of governance is unilaterally determined by technological parameters.

Another technological factor, which can determine form of governance (firm type and size) is possibility to explore technological economies of scale/scope (use of "free" resources). Generally, development of technology follows demand and is also variable parameter. Besides, maximal scale economies could be achieved not through internalization of activity but market exchange of specialized activity - e.g. selling out or purchasing a service. Free resources could also be traded (sold, leased-out) more effectively on market instead of being used in own non-specialized activity (opportunity costs).

Indeed opposite tendency is observed - dependence of technological development on governance. It is typical when institutional restrictions (land transfer, hiring labor) and high transaction costs (for outside financing/crediting) restrict realization of potential of available technologies. Widespread application of primitive technologies is a rule rather than exception. In other cases, high transaction uncertainty or imperfect institutional arrangements lead to expansion of business organization beyond "technologically optimal" scale (huge overconcentration and diversification in multinationals).
Technological development affects enormously structure and level of transaction costs. Mechanization, digitalization and standardization of operations/products increases manageability and leads to extension of activities under singe management enlarging internal (internal division and specialization of labor) and external (market/contract procurement, trade, cooperation) transactions.

\section{Crietria for efficiency of business organisation}

Better understanding the essence of economic organizations let reformulate criteria for economic efficiency. "Immediate combination" of factors of production will have to be carried such forms which optimize (minimize) total production and transaction costs of participants. Organization will be efficient if (has potential to) realize maximum possible productivity of resources with minimum transaction costs. According to that an increase in efficiency of enterprise means improving productivity with same transaction costs or decreasing transaction costs for achieving certain productivity. (Maximum) efficiency of business organization is achieved when potential for increasing productivity of resources is realized with minimum transaction costs compared to practically possible alternative organization.

Often, alternative organization (commercialization of internal transactions, transformation one-person firm into coalition) is obviously more efficient since it increases overall technological and transactional benefits with less overall costs (economies of scale/scope). If changing organization is associated with additional production benefits (reduction of production costs, growth in productivity/ quality) at the expanse of additional transaction costs (management of contract for financing, innovation, services, hiring labor), then new organization will be efficient if there is net benefit - when benefits in form of growth in output, income, free time etc. are bigger then growth of transaction costs.

Methods for assessing partial/overall productivity of resources (productivity, profitability, trade-offs current-capital costs) are well elaborated. What is a challenge is "measurement" of transaction costs. One direction for assessment is direct comparison of costs for each transaction in different forms, as organization which requires less costs is more efficient. For instance, comparison is made whether direct marketing of output is more beneficial or it is cheaper to use marketing cooperative.

Sometimes, costs of transaction are easily determined since they are object of separate accountancy or can be easily specified (costs for registration, market information, advertisement, court suits, guarding property, payment of bribes, losses from ineffective transactions). Some transaction costs are difficult/expensive or impossible to determin (costs for finding best partner, negotiation, enforcement of contracts, organizational development, interlinked transacting, unrealized/failed deals). It is often complicated to separate transaction from traditional production costs (e.g.while executing production operations manager supervises hired labor; during inputs transportation negotiates marketing of output). Approximate estimate for transaction costs could be made by interviewing managers where they indicate level of efforts/time devoted for governing different type transactions: finding needed labor, inputs for purchas/lease; negotiating exchange terms; monitoring implementation of contractual obligations; adaptation of contracts to new conditions; conflicts resolution; memberships in professional organizations; relations with government bureaucracy etc. 
Detailed comparison of transacting costs cannot always give idea for efficiency of organizations since often alternative form decreases one type while increasing another type transaction costs. For instance, internalization of transaction is associated with reduction of costs for information supply (overcoming market uncertainty), permanent (re) negotiations along with constantly changing conditions of exchange, safeguarding investments from outside opportunism but enlarges costs for organizational formation, decision-making, integral management, supervising and motivation of hired labor. Finaly, part of transactions is governed not by "pure" but complex/interlinked modes - e.g.inputs supply in "package" with know-how/service supply; joint supply inputs and credit; crediting of production against marketing of output. It is important to take into consideration overall costs for organization of transactions of different types - all external and internal transaction costs of business organisation.

\section{Comparative structural analysis}

Another direction for evaluating efficiency of diverse business organizations is Discrete structural analysis. Since it is very difficult/ impossible to determine absolute transaction costs for individual modes, assessment is made on comparative costs of alternative organizations. Besides, quantitative approach (absolute/relative measures, marginalism) is replaced by qualitative analysis and indirect assessment of transacting costs. Actually, we are interested not in absolute level of transaction costs in different forms, but in organization with lowest comparative costs for particular activity/transaction.

New approach for assessing economic organizations turns individual transaction and associated costs into basic unit of analysis. Analysis of business organizations includes following: First, major type transactions in which agent managing transactions (entrepreneurs) participates are determined. Second, feasible/alternative forms for organization of different types transactions are identified. Third, critical factors of transaction costs, and costs (and benefits) associated with alternative governing modes are specified. Forth, comparative efficiency of alternative modes is assessed, and effective boundaries of market and private organizations defined. Fifth, cases of market and private failures, and needs for public intervention identified.

Major types of transactions are associated with: labor supply, supply of land and natural resources, service supply, inputs supply, know-how supply, innovation supply, finance supply, insurance supply, marketing of services and products. Identification of employed and feasible forms for organizations in different countries, regions, subsectors is object of micro-economic survey.

Next, "critical dimensions" of transactions are determined - factors responsible for variation of transaction costs in specific economic, institutional and natural environment. They are identified as: frequency of transactions between same partners; uncertainty surrounding transactions; specificity of assets for supporting particular transaction; appropriability of rights associated with transactions.

When recurrence of transactions between same partners is high, both/all sides are interested in sustaining and minimizing costs of relations (avoiding opportunism, building reputation, setting incentive and adjustment mechanisms, conflict resolution devices). Here continuation of relations with particular partner/s and designing special mode for transacting has high economic value. Parties restrain for opportunism which detection is "punished" by turning to competitor (losing future business). Besides, costs for development of special private mode for facilitating bilateral/multilateral exchange could be effectively recovered by frequent exchange. When transaction is occasional/incidental then possibility for opportunism is great since cheating side cannot be easily punished (good reputation is not of value).

When uncertainty surrounding transactions increases, then costs for carrying and secure transactions go up (for overcoming information deficiency, safeguarding against risk). Since bounded rationality is crucial and opportunism can emerge agents will use such modes of organization diminishing transaction uncertainty. While certain risks could be diminished/eliminated by production management or market mode (e.g.purchase of insurance) most transacting risk would require special private forms - using share-rent or output-based compensation; trade with origins; providing guarantees; employing economic hostages (collateral for providing credit); participating in inputs-supply or marketing cooperative; complete integration. When transacting between same counterparts is rare, and is not supported by specific assets, and private appropriability of rights is high, then faceless market exchange is most efficient. Depending on level of uncertainty and agents risk-aversion different entrepreneurial risk is taken and normal, lower, or higher return from transactions got.

Transaction costs get very high when specific assets for relations with particular partner are to be deployed. In this case it is impossible to change partner (alternative use of assets) without big loss in value of specific capital. Relation specific/dependent investments are "locked" in transactions with particular buyer/seller and cannot be recovered/ rented through "faceless" market transactions (counterpart's "personality" matters). Costless alternative use of specific assets (loss of value) is not possible if transactions fail to occur, prematurely terminated, or less favorable terms renegotiated (in contract renewal time before end of life-span of capital). Dependant investment/assets have to be safeguarded by special form such as long-term or tied-up contract, interlinks, hostage-taking, joint investment, quasi/complete integration. Often, later is quite expensive, investment in specific capital are not made, and activity/transactions cannot take place or occurs without any comparative advantages in respect to productivity.

If high symmetrical (capacity, product, timing, location) dependency of assets of counterparts exists (regime of "bilateral trade") there are strong incentives in parties to elaborate special private mode of governance. When unilateral (asymmetrical) dependency exists then dependent side (facing mini/total monopoly) has to protect investments against possible opportunism (behavioral uncertainty/ certainty) through integrating transactions (unified organization, joint ownership, cooperative); or safeguarding them with interlinked contract, exchange of economic hostages, development of collective organization to outstand asymmetrical dependency (for price negotiation, lobbying for Government regulations).

Activity/transacting is particularly difficult when appropriability of rights on products, services, resources is low. "Natural" low appropriability has most of intellectual products (market information, meteorological forecasts, new varieties and technologies). Besides, all products and activities with significant positive/negative externalities are to be included. If appropriability is low, possibility for unwanted market/private exchange is great, and costs for protection (safeguard, detection of cheating, disputing) of private rights/investments extremely high. Because of bounded rationality, costs for protection, detection, verification, and third-party/court punishment of unwanted exchange extremely high. For transactions with low appropriability costs and benefits are independent of individual participants. Agents would either over-produce (negative externalities) or under-organize such activity (positive externalities) unless they are governed by 
efficient private or hybrid mode (cooperation, strategic alliances, longterm contract, trade secrets, public order).

\section{Effective forms for business organizations}

Individual organizations have different comparative advantages and disadvantages to maximize benefits and minimize costs of transactions with specific critical dimensions. In general, internal organization/integration has advantage for governing transaction with high uncertainty and specificity/dependency of assets, since it diminishes bounded rationality and protects investments from outside opportunism. On contrary, transactions with high certainty (bounded rationality not important) and universal character of assets (opportunism cannot be realized since transaction can be executed with another partner without additional costs) can be carried across free market without encountering costs for development of special private mode. Private organization is effective only for transactions with high recurrence between partners, since occasional/single transactions do not let recovering ("payback") investment for development of special governance mode (mechanisms for coordination, stimulation, dispute resolution; formal registration). Finally, markets and private forms are appropriate for transactions with high appropriability, since they would recover invested resources through exchange. For transaction with low appropriability private rights cannot be protected (unwanted exchange) or are enforced with extremely high costs. Thus, such transactions could be effectively governed either by hybrid (mixed public-private, quasi-public) or entirely public forms.

Since transactions have different critical dimensions and governance forms have different comparative advantages it is to be "alignment of transactions (which differ in attributes) with governance structures (which differ in costs and competence) in discriminating (mainly transaction cost economizing) way" [3]. According to combination of specific characteristics of each activity/transaction, there will be different most effective form of economic organization for that particular activity (Table 1). Transactions/activity with good appropriability, high certainty, and universal character of investments (partner can be changed anytime without significant costs) could be effectively carried across market through spotlight or classical contracts. Here organization of transactions with special form or within firm would only bring extra costs without producing any transacting benefits.

Recurrent transactions with low assets specificity, and high uncertainty and appropriability, could be effectively governed through special contract. Relational contract is applied when detailed terms of transacting are not known at outset (high uncertainty), and framework (mutual expectations) rather than specification of obligations practiced. Partners (self)restrict from opportunism and motivated to settle emerging difficulties and continue relations (situation of frequent bilateral trade). Besides, no significant risk is involved since investments could be easily/costlessly redeployed to another use/users (no assets dependency). Special contract form is also efficient for rare transactions with low uncertainty, high specificity and appropriability. Dependent investment could be successfully safeguarded through contract provisions since it is easy to define and enforce obligations of partners in all possible contingencies (no uncertainty). Here occasional character of transactions does not justify internalization within firm.

Transactions with high frequency, uncertainty, assets specificity/ dependency, and appropriability, have to be organized within the (internal ownership mode). For instance, managerial and technological knowledge is quite specific to a firm, and its supply has to be governed through permanent labor contract and coupled with ownership rights (products, assets). Capital investments in land are to be made on own/long-leased-in rather than seasonally rented land (high site and product specificity); all "critical" to firm tangible assets will be internally organized (important machinery; water supply for irrigated farming); while universal capital could be effectively financed by market form (bank credit), highly specific investments can be only made through internal funding (own funds, equity sell, joint venture).

If specific and specialized capital cannot be effectively organized within firm (economy of scale/scope explored, funding made), then effective governing form(s) outside firm-gates is to be used (joint ownership, interlinks, cooperative, lobbying for public intervention). When strong assets (capacity, technology, time of delivery, site, branding) inter-dependency with upstream/downstream partner exists, then it is not difficult to govern transactions through contract mode (strong mutual interests for cooperation and restriction of opportunism). For instance, effective supply/procurement contracts between farmers and processors are widely used in food processing industries (symmetrical dependency).

However, smallholders very often face unilateral dependency and need effective (ownership) organization to protect interests. Transacting costs for initiating and maintaining such "collective organization" are high (big number of coalition, different interests of members, "freeriding") and it is either unsustainable or does not evolve. That creates serious problems for efficiency/sustainability of individual businesses - missing markets, monopoly/quasi-monopoly situation, impossibility to "induce" public intervention.

Serious transacting problems arise when condition of assets specificity is combined with high uncertainty, low frequency, and good appropriability. Here elaboration of special governing structure for private transacting is not justified, specific investments not made, and activity/restriction of activity fails to occur at effective scale ("market and contract failure"). Similar difficulties are encountered for rare transacting associated with high uncertainty and appropriability. In all these cases, a third-part (private, NGO, public) involvement in transactions is necessary (assistance, arbitration, regulation) in order to make them more efficient or possible. Particular trilateral mode is invented such as neoclassical contract which arranges "third party participation" and manages transactions with high uncertainty and asset specificity, and low frequency. Unprecedented development of special origins, organic farming, systems of "fair-trade" are good examples. Consumer's demand (premium) for organic, original, and fair-trade products is increasing but their supply cannot be met without effective trilateral governance including independent certification and control.

When appropriability associated with transaction/activity is low, there is no pure market mode to protect and carry, activity effectively. Respecting others rights (unwanted exchange avoided) or "granting" additional rights to others could be governed by "good will" or charity actions of individual, NGOs. For instance, a great number of voluntary environmental initiatives have emerged driven by competition, producers preferences for eco-production, or responds to public pressure for sound eco-management. In any case, voluntary initiatives could hardly satisfy entire social demand especially if they require significant costs.

Some private modes could be employed if high frequency and mutual assets dependency exists such as unwritten accords, interlinking, bilateral or collective agreements, close-membership cooperatives, 


\begin{tabular}{|c|c|c|c|c|c|c|c|c|c|}
\hline \multirow{9}{*}{ Generic modes } & \multicolumn{9}{|c|}{ Critical dimensions of transactions } \\
\hline & \multicolumn{9}{|c|}{ Appropriability } \\
\hline & \multicolumn{8}{|c|}{ High } & Low \\
\hline & \multicolumn{8}{|c|}{ Assets Specificity } & \\
\hline & \multicolumn{4}{|c|}{ Low } & \multicolumn{4}{|c|}{ High } & \\
\hline & \multicolumn{8}{|c|}{ Uncertainty } & \\
\hline & \multicolumn{2}{|c|}{ Low } & \multicolumn{2}{|c|}{ High } & \multicolumn{2}{|c|}{ Low } & \multicolumn{2}{|c|}{ High } & \\
\hline & \multicolumn{8}{|c|}{ Frequency } & \\
\hline & High & Low & High & Low & High & Low & High & Low & \\
\hline Free market & ' & 'T' & & & & & & & \\
\hline Special contract form & & & $' T$ & & & ' $\mathrm{Y}$ & & & \\
\hline Internal organization & & & & & ' $\mathrm{r}$ & & ' & & \\
\hline Third-party involvement & & & & 4 & & & & $\oplus$ & \\
\hline Public intervention & & & & & & & & & $\Leftrightarrow$ \\
\hline
\end{tabular}

codes of professional behavior, alliances, internal organization. However, emerging of special (private) large-members organizations for dealing with low appropriability (satisfying entire "social" demand) would be very slow and expensive, and they unlikely be sustainable in long run (free riding). There is strong need for third-party public intervention in order to make such activity possible/ more effective (public organization, public contract, mandatory taxing, introduction of new property rights). For example, supply of "environmental goods" by farmers could hardly be governed through private contracts with individual consumers because of low appropriability, high uncertainty, and rare character of transacting (high costs for negotiating, contracting, charging potential consumers, disputing). Supply of environmental protection service is very expensive (production and organization costs) and unlikely be carried on voluntary basis. Financial compensation of farmers by willing consumers through pure market mode (tax, premium) is ineffective due to high information asymmetry and massive enforcement costs. A third-party mode with direct public involvement would make that transaction effective: on behalf of consumers State Agency negotiates with individual farmers public contract for "environment conservation service", coordinates activities of various agents, provides public payments for compensation of farmers, and controls implementation of negotiated terms.

\section{Economic boundaries of firm}

Next step is to identify range of feasible organizational forms for each generic mode for specific context of particular country, region, subsectors, and agent. For instance, specific varieties of "internal organization" in agriculture include: one-person farm or firm, family farm or firm, group farm or firm (partnership), cooperative, corporation, public farm or firm, joint venture. Corresponding forms of "free market" are: spot exchange on local, regional etc. markets; classical contract, wholesale trade etc. "Special contract form" could be: short-term contract, long-term contract, relational contract, interlinked organization, multilateral agreement etc. For completing the list of alternative organisational forms in each generic type a special micro-economic survey is needed.

Finaly effective horizontal and vertical boundaries of individual forms could be determined on basis of potential to: overcome bounded rationality and transaction uncertainty, safeguard transactions and investments from hazard of opportunism, realized economies of scale/scope of specialized and specific capital, and minimized overall (production and transaction) costs. Achieving efficiency though increasing productivity/benefits and transaction costs for each form will be quite different in specific institutional, economic and natural environment for agents with diverse characteristics and activity/ transactions with specific combination of critical dimensions. Therefore, individual organizations will have quite different efficiency and effective boundaries. Part of transactions/activity will be effectively governed through free market exchange; another part will be effectively organized through special contract mode(s); part of transactions will be entirely integrated within firms of different types, while trest protected though special private organization(s) outside firm gates.

At this stage qualitative analysis is made on comparative efficiency of diverse type of business organizations in specific socio-economic, institutional and natural environment. It is often impossible to comeasure production and transaction costs in qualitative term, but such "calculation" is always made by business managers and other agents. Also answer is given to "paradox" why a big firm cannot do the same and more than a number of small firms can do, and vice verse. Furthermore, inadequacy of indicators for productivity of production costs and resources for assessing efficiency of different business organizations becomes evident. Contrary is to be expected significant variation in rate of profitability on investments in firm (profit-making organization) from "pay-back" of expenditures and resources in cooperative (member-oriented organization), public farm (nonfor-profit organization) or subsistence farm (giving opportunity for productive use of otherwise "non-tradable" family labor, land).

Traditional statistical and other data are less suitable for testing and wide application of suggested approach. It is necessary to collect microeconomic data for diverse transactions managed by various agents and their critical dimensions though organizing interviews with managers of different type business organizations and experts in area.

\section{Specificity in agri-business innovations}

In a real (positive) transaction costs world the initial assignment of property rights between individuals could substantially deformed the total outcome efficiency. For instance, market transacting would oversupply chemical intensive innovations and undersupply environmentally friendly technologies because the relative price levels do not take into account the (negative) externalities and no third-party regulation was in place.

Firstly, the agrarian innovation is a result of a large combination of activities in the area of agricultural research, product (technology) development, agrarian extension and farming. Researchers from different branches and disciplines, and a great number of support personal, 
extension officers, farmers, and consumers of agrarian innovations participate in the process. Just one typical example is the development of new alfalfa variety with enhanced nitrogen fixation which involved contribution from science-oriented research in biochemistry, genetics, microbiology, plant physiology together with technology oriented research in plant breeding and farm management. The efforts took more than 30 years before to get to the commercialization stage and relied on both disciplinary and cross disciplinary research in several institutes [6].

Co-ordination of activities in such a large scale and time horizon could hardly be a "side" result of market competition. It usually requires complex (program, strategic alliances, collaborative privatepublic actions etc.) organization of these polyvalent links. That is why the role of the national and transnational co-ordination bodies (Academies, Joint Councils, Priority Boards etc.) becomes bigger. Besides, specific for the area modes (conferences, workshops etc.), formal governance bodies (representation committees), and informal organizations (informal Colleges) develop to facilitate transactions in different directions. In private companies the research laboratories are usually organized at the top hierarchical level where the possibility for direct control of the activity is highest.

Secondly, because of the small market appropriability (high spillovers) of some intellectual agrarian products the agents set up private modes in order to protect property rights and capture higher return on their investments. For instance, the trade secrets are broadly used to overcome inefficiency of market transacting. Besides, private partners develop variety of profit (risk) sharing arrangements (joint ventures, strategic alliances, cross equity financing of innovations etc.) to secure returns of their investments in innovation activities. Namely the large firm size is associated with successful research and development programs since only big (monopolistic) companies are able to absorb failure by innovating across broad technological front, and they have market power to reap rewards of innovations. Recent boom in direct investments, mergers and take-overs of agrarian innovation firms is the form of internalizing transactions and overcoming market risk. When uncertainty and therefore possibility for moral hazard in technology transfer is high (developing countries) then the lump-sum instead of output-based royalty payment is the preferred mode for organization of transaction [7].

Next, when some of the party makes highly specific to a transaction investments he/she either can lose their value (if transaction does not occur or prematurely terminated) or he may face unfavorable trading conditions when the transacting recurrent time comes [3]. When investments are "lock up" with a particular transaction they are usually protected by some form of a long-term contract or ownership integration. For instance, investments in human capital of scientists are highly specific to a particular area of research or even a project. Productivity of idiosyncratic to a person (firm) capital is much smaller under alternative use and it can not be transferred to other uses without big lost in value. Researchers would not invest in highly specific to the transactions capital if they are not governed by a stable organization such as a permanent employment contract. Also specific forms develop to secure long-term commitment of transacting sides (e.g. sharing of training costs between employee and employer) and to stimulate individual investments in the specific capital (regulation of researchers salary, tenure contracts etc.).

In the same way, when a private company finances public research or acquires know-how from a private laboratory it would secure payback of its specific investments by a license contract for exclusive commercial use. When assets are in high bilateral dependency then tight vertical integration of transaction is the common mode. For instance, if innovation investments are in high symmetrical interdependency with manufacturing, marketing etc. assets of a company then they are always integrated in a common structure. Studies also show that the full ownership integration through in-house research (in-souring) is the dominant mode for major (core) projects of private firms, and out-souring form is used for complementary projects and topping in superior knowledge [8]. That is also the reason why equity rather than debt (e.g. bank loan) financing is the most likely form for funding of the risky investments in specific intangible assets (patents, trade secrets, know-how, organizational culture etc.).

Forth, because of the information asymmetry and the high uncertainty a party can be exposed to opportunistic behavior before or during execution of transactions (e.g. the difficulties to verify quality of new agro-chemical, the proper expertise of researcher competing for a project grant or for a position etc.). In order to overcome transacting difficulties partners would prefer to rely on more effective than (spot) market form of organization such as brand name, demonstration, guarantee in the first case, or reputation consideration, pear review, or apprenticeship in the second.

The interlinked mode of transacting with the industry is a common mode for introduction of new technologies in farming and "free" extension service is supplied in a package with input supply transactions. When there is a mutual (capacity, technology, quality, timing of delivery) assets dependency a long-term contract is preferable form to govern transactions. Such strong bilateral co-ordination between farmers and processor exist in beef, swan, and poultry industries, and it is supported by tight interlinked marketing, inputs, innovation and extension supply contracts, and a total production management or even a complete vertical integration by a processor. Similarly, in public institutions more "market like" mechanisms are extensively introduced (direct financing from industry, fees for service etc.) to interlink incentives (transactions) to real demand of ultimate customers of agrarian innovations.

Fifth, very frequently participants in the innovation process face missing market for some products and services - e.g. highly specialized scientific equipment, qualified labor, know-how etc. That is why they have to develop these activities as internal or joint (non-for-profit or professional) organization. For instance, on-job training is usually a part of the innovation project; scientific equipment design is a subproject or involves a strong contribution by researchers who will eventually use it. Also various consortiums and joint ventures are organized in a large multinational scale for mutual exchange of know how, biological materials etc.

Sixth, otherwise beneficial for all parties innovation transactions would fail to occur at optimal scale if there is no agrarian intellectual property rights protection or its enforcement is very expensive (e.g. new self-pollinated varieties), or if monopoly rights on some innovations bring a market distortion. In this case participants in the agrarian innovations (farmers, researchers etc.) have to develop an organization for public good demand for a third party (local authority, central Government, foreign assistance programs) involvement in innovation transactions. The outcome could be some kind of regulations of transactions (price ceilings, mandatory testing for safety standards), introduction of new monopoly rights on intellectual agrarian products in order to increase incentive for ownership organization, enforcement of special modes for organization of private transacting (e.g. mandatory licensing), introduction incentives (subsidies, tax breaks, international transfer 
liberalization) for private investment in innovation, assisting "quasi" public organization of innovation (e.g. mandatory levies for collective supply of research and development), public financing of innovation activities, in-house organization and direct public provision of agrarian research and extension service.

It is always necessary to asses various alternative modes for thirdparty involvement in particular innovation in comparative (transaction costs minimizing) way. For instance, when costs for introduction and enforcement of agrarian intellectual property rights are enormous for all parties then other options for intervention have to be considered. The experience shows that while property right modernization on biological innovation has had a significant impact on private research and development in the USA and Europe, in many Latin American countries there is no or only weak evidence for such an impact [9].

If transaction cost for organizing of competitive funding of public institutions is high (for writing and evaluating proposals, rent-seeking and lobbying, avoiding friendships, finding buyers for research products, and lost opportunity as a result of unproductive use of researchers time) then core funding is to be undertaken. Moreover, if intensity of transacting is not big (a small country size) and foreigners are not allowed in competition that mode would involve only additional costs without any benefits. Specialized research market exists only in large countries, and usually a small numbers (quasi monopoly) condition prevails. Bidding participants with highly specialized for a project human, infrastructure etc. capital always will win. Even if there is a big number competition initially it would turn to a small number condition when project extension time comes ("Fundamental process transformation" in Williamson's term).

Seventh, the technological nonseparabality of activities is not an important factor which could determine the minimal size of innovation organization. It is almost impossible to give examples in research and innovation where organization form is unilaterally determined by the technology. Usually there are plenty of alternative modes for organization of agrarian activity under the same research (innovation) technology and methodology. For instance, development of new variety could be organize by the state research institute, university department, stand-along or in-house private laboratory, by contract with a research team, by collective (farmers) organization, by hybrid mode, imported (transferred) from abroad through license agreement or from international research centre.

Thus the individual agent (basic unit of transacting) also determines the minimal possible size of innovation organization. Beyond this size various private, public, and mix (hybrid) organizations develop to realize technological and transaction economy of scale and scope in the innovation process. For instance, size of internal organization of activity (transactions) in specialized or related activities will increase as far as some potential to realize technological economy of size/scale exists (overhead, building, library etc.). The potential for managerial economy is also great in innovations. Instead of transacting with each individual (high asymmetry of information) the funding agency sings a contract with a leading scientist or delegates executive rights to an administrator. In this way all sides save large costs for finding best partners, negotiating conditions of exchange, writing and disputing contracts, current adjustment during contract execution stage etc. That is how program (project) organization develop in the innovation area. It combines top-down direction (long-term co-ordination) with the decentralized bottom-up management ("self-organization" of research). Besides, research (innovation) management separates in a condition of funding crisis of research and development, and it is a specialized activity of proposal writing, lobbying for success, subcontracting execution etc.

Very frequently modern research projects require minimum size and team efforts to be successful at all. Moreover, the ideal (non rival) character of the scientific knowledge allows the maximum economy to be realized at national and more commonly at international scale. Innovation also becomes increasingly an expensive venture and requires reducing unnecessary duplication (competition) of activities. The strong co-operation to enhance productivity and share risk (natural "dry holes") is a norm rather then exception in the innovation process. Much private company practice tapping in the university or public research through joint venture and collaborative agreements. In this way they use outside capacity without extending transactions trough expensive internal modes (e.g. employment contracts). Also various hybrid modes such as strategic alliances, develop to increase managers control on the innovation process without loosing incentives for innovation as it is in hierarchical modes. Alliance organization has big advantages in conditions of high uncertainty since they allow flexibility in exploring (outside) economy of scale without involving big idiosyncratic investments (low exit cost).

Since pre-patent competition is a large public waste, a new trilateral form for organization of transactions has been invented. Here public subsidy is given to productive researchers and they are allowed to patent publicly funded inventions. In this way the competition (and unnecessary duplication) is restricted only to proposal writing stage since afterward winning (subsidized) researchers have comparative advantages in getting positive results. This mode preserves the powerful ("market like") incentives in competing for the public grants and for obtaining the private property rights on output.

When frequency of transactions in horizontal or vertical directions is very high then an internal organization save repeated costs of market transacting. Instead of renting a land plot for research experiments year after year, a long lease or ownership mode is used. In this way, different functional, problem, location specific, commodity or customer oriented organizations for innovation are developed. The internalization of transacting is pushed ahead when specificity of investments increases. Here continuation of relationships with a particular partner(s) has high value. Also efforts (long-term costs) to design a special mode are justifies since they can be recovered for repeated transacting (current costs saving). For instance, the extension supply transactions become highly location and farm specific. That is why these transactions are broadly internalized by a joint ownership mode (e.g. farm associations) as a form for exploring the economy of scale on a highly specific to members capital.

When frequency of internal transacting in not very high and assets are not in a bilateral dependency, then the internal organization occurs only additional management costs without any extra benefits. This is why innovation activities in agriculture is to be distributed between a number of specialized organizations instead of carrying out all transacting in a nation-wide company.

Technology and its development is very important for determining the effective size of innovation organization. That is particularly important in transaction cost minimizing respect. The development in information and communication technologies revolutionaries organizations for transactions as well. The introduction of Internet for instance, makes the costs close to zero for a large part of innovation related transacting. It intensifies research and development through cheap direct transactions between individuals and on-line arrangements 
of informal modes in a big (practically world-wide) scale. It also decreases time and costs of finding best partners for co-operation and trade, for access to innovation data base, for searching for the best prices of agrarian innovations, for invention promotion, for public disclosure of cheating etc. All these development started to replace the traditional (old) model for innovation organization bringing to life effective small-size operations both in public and private sector.

\section{Effective modes for organization of agrarian innovations}

The governance matrix for organization of various input supply and marketing transactions in agrarian innovations is summarized in Table 2. Most effective modes differ according to the type of transacting, and depends on combination of appropriability, assets specificity, uncertainty and frequency of transactions [10]. When appropriability is high, there is no asset dependency, uncertainty is low, and frequency is high then market is the best mode for organization of innovation transacting. When appropriability is high, but assets are on increase specificity regime, and transaction is characterized by high uncertainty and frequency then private organization based on ownership or tight integration comes up to be the most effective. However, when appropriability decreases, and assets specificity and uncertainty is high, then market and private transactions fail to occur at effective scale. Then a strong necessity for a third part (government) involvement in innovation transacting comes to agenda. The development of agrarian innovation system would be substantially deformed if effective modes for public involvement (assistance, regulation, public provision etc.) are not introduced in due time [11]

When the modes for government interventions are designed then the critical dimensions of transactions, and the comparative advantages of different forms (to improve incentives, decrease information asymmetry and overcome the possibilities for opportunism in the innovation process) are to be taken into account.

\section{Effective modes for public intervention}

There is a big variety of possible forms for public intervention in market and private transacting. The comparative institutional analysis of public modes is to include: firstly, the correspondence of the public involvement to the real needs of agrarian innovation and development (identified needs for a third-party intervention in Table 1). Secondly, the comparative advantages of alternative modes for public involvements comprising all costs - direct (tax payer, assistance agency) expenses, and transacting costs of bureaucracy (coordination, stimulation, mismanagement), and costs for individuals' participation and usage of public modes (expenses for information, paper works, payments of fees, bribes, etc.), and costs for public control and reorganization of bureaucracy. And third, the comparative efficiency of selected form and other feasible modes of governance - partnerships with private sector; property rights modernization etc. Accordingly, public intervention is to be initiated only if there is a net benefit - when effects are greater than additional (individual and social) costs for the third-party involvement [12].

Depending on the uncertainty, frequency, and necessity for specific investment of public involvement there will be different the most effective forms. Principally, the interventions with low uncertainty and assets specificity would require smaller Government organizations (more regulatory modes; general laws and contract enforcement). When uncertainty and assets specificity of transactions increases then a special contract mode would be necessary - public contracts for provision of private services, public funding (subsidies) of private activities, temporary labor contract for carrying out special public programs, leasing out public assets for private management etc. And when transactions are characterized with high assets specificity, uncertainty and frequency, then an internal mode and bigger public organization would be necessary - e.g. permanent employment contracts, in-house integration of crucial assets in a specialized state agency or public institute.

In the beginning, the existing problems (difficulties, costs, failures) in organization of market and private transactions have to be specified. The appropriate government involvement would be to create environment for: decreasing uncertainty surrounding transactions, increasing their intensity; protecting and making less dependent private investment. For instance, State establishes quality and safety standards for agrarian inputs, technologies and produces, certifies service providers, regulates employment relations, etc. All that facilitates and intensifies (market and private) transactions.

Next, practically possible modes for increasing appropriability of transactions have to be considered. The low appropriability is often caused by unspecified or badly specified private rights. In some cases, the most effective government intervention would be to introduce and enforce new private property rights - e.g. rights on natural, biological, and environmental resources; private rights on intellectual agrarian property and innovation etc. The later would be efficient when privatization of resources or introduction (and enforcement) of new rights is not associated with significant costs (uncertainty, recurrence and level of specific investment is low). That Government intervention effectively transfers the organization of transactions into market and private governance, liberalize market competition and induce private incentives (and investments) in certain activities .

In other instances, it would be efficient to put in place regulations for activity, trade and utilization of resources - e.g. standards for labor, product quality, environmental performance, animal welfare; norms for using natural resources, GM crops, and (water, soil, air, comfort) contamination; ban on application of certain chemicals or technologies; foreign trade regimes; mandatory training and licensing of farm operators etc. In other instances, using the incentives and restrictions of tax system would be the most effective form for intervention. Different sorts of tax preferences (exception, breaks, credits) are widely used to create a favorable condition for agrarian research and innovation. On the other hand, the taxation on emissions or products is broadly applied to reduce negative externalities (environmental degradation and pollution).

In some cases, public assistance and support to private organizations in the best mode for intervention. Large agrarian research and development programs have been widely used in all industrialized countries. They let "proportional" development of agriculture, and improvement of farmers welfare ("income parity") etc. For instance, public financial support for research, extension and innovation activities of universities, and collective and private organizations is commonly used instrument for improving economic and eco-performance of farmers and accelerate agrarian development. Often providing public information, recommendations, training and education to farmers, other agrarian agents, and consumers are the most efficient. In some cases, pure public organization (in-house production, public provision) will be the most effective as in the case of basic agrarian research, education, agro-market information, agrometeorological forecasts, border sanitary and veterinary control etc. 


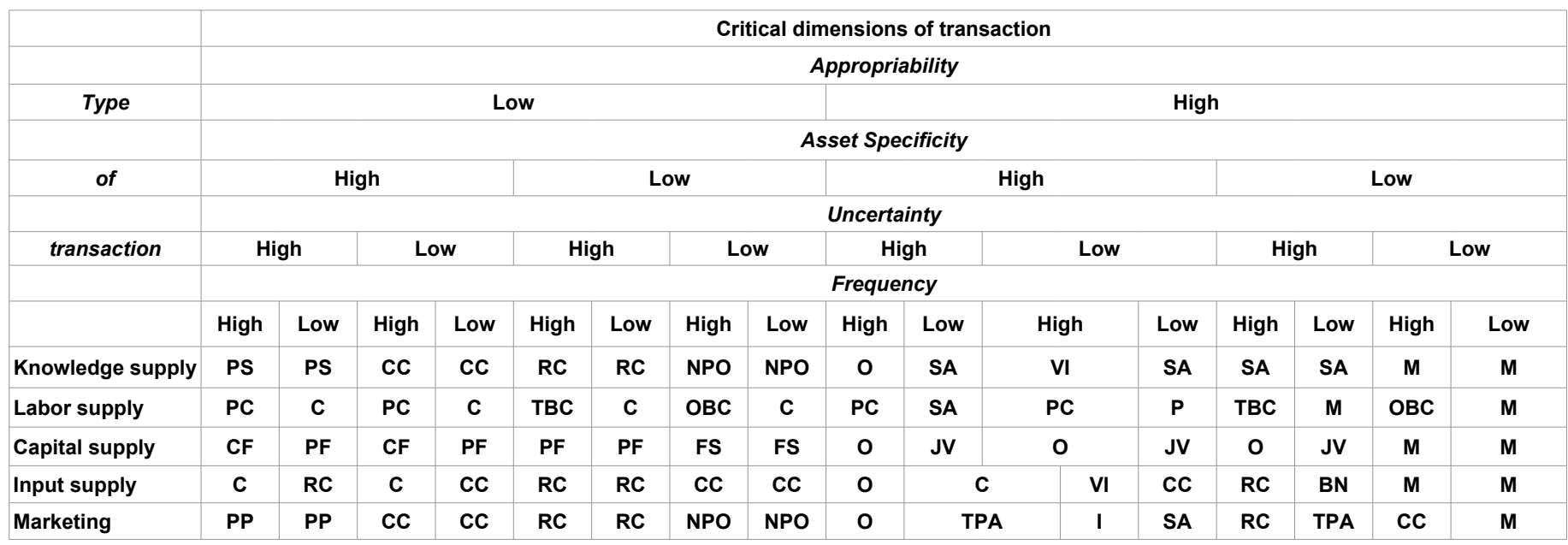

Note: Modes of transacting: M - market, CC - classical contract, RC - rational contract, I - interlinked contract, O - ownership, JO - joint ownership, P - partnership, C - cooperative (corporation), VI -vertical integration, SA - strategic alliance, PC - permanent employment contract, TBC c- time based employment contract, OBC - output based employment contract, BN - brand name, TPA - third part arbitration, PS - public supply, PP - public provision, PF - public financing, CF- collective financing, FS - fee for service financing, NPO - non profit organization

Table 2: Alternative Modes for Organization of Agrarian Innovation.

Usually, the specific modes are effective if they are applied alone with other modes of public intervention. The necessity of combined intervention (governance mix) is caused by the complementarities (joint effect) of individual forms; possibility to get extra benefits (e.g. "crosscompliance" requirement for participation in support programs); particularity of problems to be tackle; specific critical dimensions of governed transactions; uncertainty (little knowledge, experience) associated with the impact of new forms; capability of the Government to organize (administrative potential to control, implement) and fund (budget resources and/or international assistance) different modes; and not least important the dominating (right, left) policy doctrine in each country.

Besides, the level of effective public intervention (governance) depends on kind of the innovation. There are public involvements which are to be executed at local (community, regional) level, while other requires nationwide governance. And finally, there are activities, which are to be initiated and coordinated (governed) by international (regional, European Union, worldwide) level due to the strong necessity for trans-border actions (needs for cooperation in research and innovation, exploration of economies of scale/scale, governing of spill-overs) or consistent (national, local) government failures.

The public (regulatory, inspecting, provision) modes must have built special mechanisms for increasing competency (decrease bounded rationality and powerlessness) of bureaucrats, beneficiaries, interests groups and public at large as well as restricting possible opportunism (mismanagement, cheating, interlinking, abuse of power) of public officers and other participants. It could be made by training, introducing new assessment and communication technologies, increasing transparency (independent assessment, audit), and involving experts, beneficiaries, and interests groups in management of public modes at all levels. Furthermore, applying "market like" mechanisms (competition, actions, licensing etc.) in public projects design, selection and implementation would significantly increase incentives and decrease overall costs.

Principally, pure public organizations should be used as a last resort when all other modes do not work effectively. The "in-house" organization has higher (direct and indirect) costs for setting up, running, controlling, reorganization, and liquidation. Unlike market and private forms there is not an automatic mechanism (competition) for selecting the most effective modes. Public "decision making" is required which is associated with high costs and time, and it is often influenced by strong private interests (power of lobbying groups, policy makers and their associates, employed bureaucrats). Along with the development of the general institutional environment ("The Rule of Law") and measurement, communication etc. technologies, the efficiency of pro-market modes (regulation, information, recommendation) and contract forms would get bigger advantages over the internal less flexible public arrangements.

Usually hybrid modes (public-collective-private partnership) are much more efficient than pure public forms given the coordination, incentives, and control advantages. In majority of cases, involvement of researchers, stake-holders and other beneficiaries increase efficiency - decrease asymmetry of information, restrict opportunisms, increase incentives for private costs-sharing, reduce management costs etc. Principally, researchers and innovators posses information superiority, and exists strong interlinks of activity (economy of scope), high assets specificity to person, team or organization (competence, high cite-specificity of investments). Furthermore, outside directing and/or enforcement of most part of innovation activities is often very difficult or impossible at all. In all these cases, stimulating and supporting (assisting, funding) collective and private actions are much more effective then mandatory public modes in terms of incentive, coordination, enforcement, and disputing costs (Bachev 2007).

Anyway, if there is a strong need for a third-party public involvement but an effective government intervention is not introduced in a due time then the agrarian "development" would be substantially deformed (Government failure is possible). As a matter of fact, the later is quite common in agrarian research and development across the world - most studies show a high return on investment in R\&D and thus constant public under-investment in that important area of social activity since last century now.

\section{Conclusion}

In textbook economy "without institutions and transaction costs" theory of business organization in agriculture is very simple - there is no economic need for organizations. There is single mechanism for 
Citation: Bachev H (2014) About Management and Efficiency of Agri-Business Organisations. Int J Econ Manag Sci 3: 188. doi: 10.4172/2162-6359.1000188

governing (coordinating, stimulating) overall activities (free market. "Situation of efficiency" is easily achieved since agents (individuals, households, firms) automatically and costlessly adapt behavior according to movements of market prices and changes in technologies. In real economy with diverse agents, institutions and transaction costs there is place for other effective (non-market) modes for organization - firms of different types, contracts, public and hybrid forms. "Old" problem of efficiency finds "new" dimension through incorporation into analysis of transaction costs as focus is on assessment of comparative efficiency of all (rather then part) of alternative modes of economic organizations. Also it becomes absurd traditional "black box" approach in analysis of different type of firms and productivity as sole indicator for their efficiency.

Suggested new framework helps us better understand factors for organizational choice and efficiency, and needs for public intervention in agriculture. Analysis of transaction costs identifies immense range of "market failures" associated with badly specified property rights and inefficient system for enforcement; high uncertainty and dependency of activity, low appropriability etc. Private agents "deal" with market deficiency developing different non-market forms for effective governance (contracts, internal modes, trilateral private organization, collective actions). However, private sector also "fails" to safeguard individual rights and carry out certain activities at effective scale. There is strong need for a third-party public involvement in market and private transactions though institutional modernization, assistance, regulation, hybrid or in-house organization. Agrarian development is compromised when market and private sector fail, and no effective public intervention takes place - imperfect institutional structure is not reformed, delayed or bad government interventions prevail, fruitless international assistance dominate, and needed global governance not established.

\section{References}

1. Coase $R$ (1937) The Nature of the Firm, Economica 4: 386-405.

2. Furuboth E, Richter R (1998) Institutions and Economic Theory: The Contribution of the New Institutional Economics, The University of Michigan Press, Ann Arbor.

3. Williamson O (1996) The Mechanisms of Governance, Oxford University Press New York.

4. Coase R (1960) The Problem of Social Costs, Journal of Law and Economics $3,1-44$.

5. Olson M (1969) The Logic of Collective Actions: Public Goods and the Theory of Groups, Cambridge: Harvard University Press.

6. Heichel G (1987) Anticipating Advances in Crop Technology, in Policy for Agricultural Research, Westview Press, Boulder.

7. Larson B, Anderson M (1994) Technology Transfer, Licensing Contracts, and Incentives for Further Innovation, American Journal of Agricultural Economics 76.

8. Ulset S (1996) R\&D Outsourcing and Contractual Governance, Journal of Economic Behavior \& Organization 1:80-95.

9. Perrin R (1994) Intellectual Property Rights in Agricultural Development, in Agricultural Technology: Policy Issues for the International Community, CAB International, Cambridge.

10. Bachev H, Labonne M (2000) About Organization of Agrarian Innovations, INRA, Montpellier.

11. Bachev H (2004) Efficiency of Agrarian Organizations, in Farm Management and Rural Planning No 5, Kyushu University, Fukuoka, 135-150.

12. Bachev H (2007) Governing of Agrarian Sustainability, ICFAI Journal of Environmental Law, ICFAI University, Vol.VI, No 2, Hyderabad, 7-25.
Citation: Bachev H (2014) About Management and Efficiency of Agri-Business Organisations . Int J Econ Manag Sci 3: 188. doi: 10.4172/2162-6359.1000188

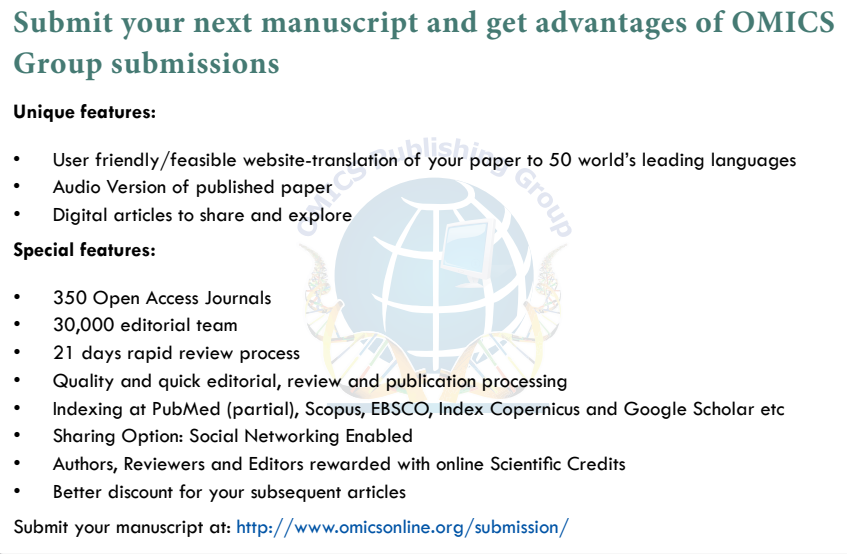

